HORTSCIENCE 26(2):180-182. 1991.

\title{
Drought Avoidance Mechanisms of Selected Bermudagrass Genotypes
}

\author{
K.L. Hays ${ }^{1}$, J.F. Barber ${ }^{2}$, M.P. Kenna ${ }^{2}$, and T.G. McCollum ${ }^{2}$ \\ Department of Horticulture and Landscape Architecture, Oklahoma State \\ University, Stillwater, OK 74078-0511
}

Additional index words. total nonstructural carbohydrate, root mass, canopy temperature, Cynodon dactylon

\begin{abstract}
This study was conducted to determine rooting characteristics, root carbohydrate content, and performance of 10 bermudagrass [Cynodon dactylon (L.) Pers.] genotypes exposed to drought. A greenhouse study was conducted twice to determine root distribution and carbohydrate content throughout the soil profile during simulated drought stress. Root distribution among genotypes and accumulation of total nonstructural carbohydrate within roots differed with depths. Root mass at 30, 60, 90, and 150 cm was significantly correlated with turf quality during drought stress $(r=0.72,0.86$, 0.80 , and 0.81 , respectively) only for one of the two tests. Root carbohydrate distribution was not significantly correlated with turf quality for the selected bermudagrass genotypes.
\end{abstract}

Selection of turfgrass species or cultivars that are adapted to humid or arid climates is often governed by water usage. Turfgrass breeders would like to develop cultivars that can flourish during periods of adequate rainfall yet retain turf quality during drought stress. One method of identifying desired turfgrasses is to select genotypes with drought avoidance characteristics.

Drought avoidance is accomplished by turfgrass anatomical and morphological adaptations that allow for sufficient water uptake, reduction in water use, or both (Beard, 1973). Interspecific differences in the ability

Received for publication 12 June 1989. Journal Article no. 5624 of the Agr. Expt. Sta., Oklahoma State Univ., Stillwater. This research was supported in part by a grant from the Oklahoma Turfgrass Research Foundation. The cost of publishing this paper was defrayed in part by the payment of page charges. Under postal regulations, this paper therefore must be hereby marked advertisement solely to indicate this fact.

${ }^{1}$ Former Graduate Research Assistant.

${ }^{2}$ Assistant Professor. of warm-season and cool-season grasses to distribute the root systems downward in the soil profile in response to drying soil have been documented (Bennett and Doss, 1960; Doss et al., 1960; Evans, 1978; Sheffer et al., 1987). Some grass species differ intraspecifically in the ability to distribute roots deeper in the soil profile as a drought avoidance mechanism (J.F.B. and R.C. Shearman, unpublished data). Research with spring wheat (Triticum aestivum L.) demonstrated that when moisture was limited, an extensive root system gave one cultivar an advantage over six others in avoiding yield reductions (Hurd, 1968).

Increases in soluble carbohydrates, free amino acids, amides, and bound water are associated with the morphological changes in plant response to drought stress (Kemple and McPherson, 1954). Carbohydrate reserves are essential for the survival and production of plant tissues when respiration rate exceeds photosynthetic activity (Smith, 1969). Total nonstructural carbohydrate concentration is an estimate of the carbohydrate en- 
Table 1. Visual quality ranking and total top growth of 10 greenhouse-grown bermudagrass genotypes following a 60-day drought stress by progressively lowering irrigation depth.'

\begin{tabular}{llcc}
\hline \hline & \multicolumn{2}{c}{ Visual quality ranking } & \\
\cline { 2 - 4 } Genotype & Expt. 1 & Expt. 2 & Top growth $(\mathrm{g})^{\mathbf{x}}$ \\
\hline $47-4$ & $8.5 \mathrm{a}$ & $7.0 \mathrm{bc}$ & $9.8 \mathrm{bcd}$ \\
$1-7$ & $7.3 \mathrm{ab}$ & $5.8 \mathrm{~cd}$ & $10.8 \mathrm{bc}$ \\
$45-3$ & $7.3 \mathrm{ab}$ & $8.0 \mathrm{ab}$ & $10.9 \mathrm{~b}$ \\
U-3 & $7.0 \mathrm{ab}$ & $2.8 \mathrm{ef}$ & $9.7 \mathrm{bcd}$ \\
$8-7$ & $6.5 \mathrm{abc}$ & $4.3 \mathrm{de}$ & $13.9 \mathrm{a}$ \\
$40-3$ & $5.0 \mathrm{abcd}$ & $10.0 \mathrm{a}$ & $9.2 \mathrm{cbd}$ \\
$47-3$ & $4.8 \mathrm{bcd}$ & $7.3 \mathrm{bc}$ & $9.9 \mathrm{bcd}$ \\
Midiron & $3.3 \mathrm{~cd}$ & $2.0 \mathrm{f}$ & $8.9 \mathrm{~cd}$ \\
Tifgreen & $3.0 \mathrm{~cd}$ & $1.8 \mathrm{f}$ & $9.1 \mathrm{bcd}$ \\
$1-8$ & $2.5 \mathrm{~d}$ & $6.3 \mathrm{bcd}$ & $8.3 \mathrm{~d}$ \\
\hline
\end{tabular}

${ }^{7}$ Means in a column followed by same letter not significantly different at $P=0.05$ using least square means procedure.

${ }^{y}$ Visual quality was ranked from 1 to $10(10=$ best $)$; means represent the average of four replications.

${ }^{x}$ Top growth weights were averaged over four blocks and two replications in time.

Table 2. Mean root weights at various soil depths for all tested genotypes.

\begin{tabular}{|c|c|c|c|c|c|c|}
\hline \multirow[b]{3}{*}{ Genotype $^{y}$} & \multicolumn{6}{|c|}{ Root wt $(\mathrm{g})^{2}$} \\
\hline & \multicolumn{6}{|c|}{ Depth $(\mathrm{cm})$} \\
\hline & $0-15$ & $15-30$ & $30-60$ & $60-90$ & $90-120$ & $120-150$ \\
\hline & \multicolumn{6}{|c|}{ Expt. 1} \\
\hline $1-7$ & 1260 & $788 \mathrm{ab}$ & 892 a & $240 \mathrm{ab}$ & $140 \mathrm{ab}$ & 82 \\
\hline $47-4$ & 1310 & 849 a & $778 \mathrm{abc}$ & $207 \mathrm{abc}$ & $116 a b c$ & 105 \\
\hline $40-3$ & 1070 & $760 a b$ & $814 \mathrm{a}$ & $258 \mathrm{a}$ & $161 \mathrm{a}$ & 73 \\
\hline $1-8$ & 1080 & $755 \mathrm{ab}$ & $791 \mathrm{ab}$ & $190 \mathrm{abc}$ & $67 \mathrm{~cd}$ & 28 \\
\hline $45-3$ & 1160 & $570 \mathrm{bc}$ & $623 \mathrm{abcd}$ & $196 \mathrm{abc}$ & $106 a b c$ & 94 \\
\hline 8.7 & 1370 & $531 \mathrm{bc}$ & $481 \mathrm{~d}$ & $133 \mathrm{~cd}$ & 94 bcd & 79 \\
\hline Midiron & 1040 & $452 \mathrm{c}$ & 532 bcd & $165 \mathrm{bcd}$ & $119 a b c$ & 97 \\
\hline $\mathrm{U}-3$ & 872 & $491 c$ & $499 \mathrm{~cd}$ & $144 \mathrm{~cd}$ & 97 bcd & 72 \\
\hline $47-3$ & 992 & $463 c$ & $415 \mathrm{~d}$ & $92 \mathrm{~d}$ & $47 d$ & 39 \\
\hline \multirow[t]{2}{*}{ Tifgreen } & 771 & $397 c$ & 530 bcd & $162 \mathrm{bcd}$ & $102 \mathrm{bcd}$ & 80 \\
\hline & \multicolumn{6}{|c|}{ Expt. 2} \\
\hline 47.4 & $2020 \mathrm{~b}$ & 681 a & $420 \mathrm{a}$ & 292 a & 166 a & $70 \mathrm{bcd}$ \\
\hline $8-7$ & 2610 a & $545 a b$ & $244 \mathrm{~b}$ & $125 \mathrm{~cd}$ & $39 \mathrm{~cd}$ & $4 d$ \\
\hline $47-3$ & $1870 \mathrm{bc}$ & $633 \mathrm{a}$ & $301 \mathrm{ab}$ & $212 a b c$ & $115 \mathrm{ab}$ & $81 \mathrm{bc}$ \\
\hline $1-7$ & $1820 \mathrm{bc}$ & $526 \mathrm{abc}$ & $289 \mathrm{~b}$ & $193 \mathrm{abc}$ & $93 \mathrm{bc}$ & $61 \mathrm{bcd}$ \\
\hline $40-3$ & $1250 \mathrm{dc}$ & 448 bcd & $291 \mathrm{~b}$ & $274 a$ & $173 \mathrm{a}$ & 178 a \\
\hline $45-3$ & $1280 \mathrm{de}$ & $426 \mathrm{~cd}$ & $281 \mathrm{~b}$ & $226 \mathrm{ab}$ & $131 \mathrm{ab}$ & $109 a b$ \\
\hline $1-8$ & $1440 \mathrm{~cd}$ & $469 \mathrm{bcd}$ & $232 \mathrm{~b}$ & $158 \mathrm{bcd}$ & $72 \mathrm{bc}$ & $62 \mathrm{bcd}$ \\
\hline U-3 & $1080 \mathrm{de}$ & $389 \mathrm{~cd}$ & $221 \mathrm{~b}$ & $85 \mathrm{~d}$ & $38 \mathrm{c}$ & $12 \mathrm{~cd}$ \\
\hline Tifgreen & 943 ef & . $344 \mathrm{~d}$ & $166 \mathrm{bc}$ & $134 \mathrm{bcd}$ & $88 \mathrm{bc}$ & $52 \mathrm{bcd}$ \\
\hline Midiron & $467 \mathrm{f}$ & $134 \mathrm{e}$ & $94 \mathrm{c}$ & $60 \mathrm{~d}$ & $38 \mathrm{c}$ & $42 \mathrm{bcd}$ \\
\hline \multicolumn{7}{|l|}{ ANOVA } \\
\hline Genotype (G) & NS & $* *$ & $* *$ & * & $*$ & NS \\
\hline Experiment (E) & * & $*$ & $*$ & $*$ & $*$ & $*$ \\
\hline$G \times E$ & $* *$ & . * & $*$ & $*$ & $*$ & $* *$ \\
\hline
\end{tabular}

${ }^{2}$ Means in a column followed by same letter not significantly different.

Genotypes arranged according to total root weight for each experiment.

${ }^{* *, \mathrm{Ns}}$ Significant at $P=0.05,0.01$, or nonsignificant, respectively.

Table 3. Correlation coefficients $(r)$ indicating dependence of visual quality on root weight of total roots in each section after 60-day drought stress by progressively lowering irrigation depth (Expt. 2).

\begin{tabular}{lc}
\hline \hline Depth $(\mathrm{cm})$ & Correlation coefficient $(\mathrm{r})$ \\
\hline $0-15$ & 0.34 \\
$15-30$ & 0.56 \\
$30-60$ & $0.72^{*}$ \\
$60-90$ & $0.86^{* *}$ \\
$90-120$ & $0.80^{* *}$ \\
$120-150$ & $0.81^{* *}$ \\
\hline
\end{tabular}

Significant at $P=0.05$ or 0.01 , respectively.

ergy readily available to the plant (Smith, 1969; Weinmann, 1947).

This study was conducted to evaluate the response of 10 bermudagrass genotypes to simulated drought stress. Patterns of distri-
1985). Tubes were cut into five $30-\mathrm{cm}$ segments with the upper $30 \mathrm{~cm}$ divided into two $15-\mathrm{cm}$ segments. The tubes were taped together with duct tape before being filled with growing medium. Fritted clay was used for the growing medium due to its water retention properties (van Bavel et al., 1978).

A single. bermudagrass sprig with four nodes was planted in each tube and allowed to establish a canopy covering the entire surface of the tube before the drought stress treatment was initiated. The canopy was formed within 45 days after planting in both experiments. Each column was irrigated at the surface daily for 30 rein, which was sufficient to saturate the medium and allow drainage out the bottom of the column. Columns were fertilized daily with a nutrient injection system (Ratio: Feeder, H.E. Anderson, Muskogee, Okla.) -to maintain a $\mathrm{N}$ level of $4.88 \mathrm{~g} \cdot \mathrm{m}^{-2}$ per month using a solution of $28 \mathrm{~N}-8 \mathrm{P}-18 \mathrm{~K}$. Four $400-\mathrm{W}$ metal halide lamps suspended $46 \mathrm{~cm}$ above the canopy were used to simulate a 14-hr photoperiod. The greenhouse was maintained at a 29/21C (day/night) sequence. Plants were clipped at $3.5 \mathrm{~cm}$ every 5 days. Clippings were collected and dried for $48 \mathrm{hr}$ at $49 \mathrm{C}$ throughout the duration of the experiment to measure total top growth during the drought treatment. Top growth for each genotype was averaged over both experiments because there was no experiment $\times$ genotype interaction.

After the canopy was formed in both experiments, simulated drought stress was induced by systematically lowering the available moisture in the soil profile. Irrigation was supplied to the top of each tube segment by two drip tubes either at the soil surface or $15,30,60,90$, or $120 \mathrm{~cm}$ below the surface. A manifold with gate valves was used to determine which depth received irrigation. This system simulated drought stress by lowering the irrigation depth from $\mathrm{O}$ to $120 \mathrm{~cm}$ at 10-day intervals.

Root mass and total nonstructural carbohydrate (TNC) concentration in roots were determined for each section of the PVC columns. Canopy temperature was measured at 10-day intervals, corresponding to the drying cycle, using infrared thermometry (Scheduler Plant Stress Monitor, Standard Oil Engineering, Solon, Ohio). Visual quality observations were made at 10-day intervals for all genotypes by ranking plants on a scale from 1 (lowest) to 10 (highest). High quality plants were green with minimal leaf marginal necrosis and wilt. Visual quality rankings at the end of both experiments were used to identify bermudagrass genotypes with superior drought avoidance capabilities on the assumption that plants of high visual quality were avoiding the simulated drought stress better than plants that were wilted and discolored.

Top growth and root segments were harvested 10 days after irrigation began at the $120-\mathrm{cm}$. level. Top growth was removed at the soil surface and added to the clippings. The PVC columns were sliced at each segment and the root material was recovered at each section by gently washing away all of 
Table 4. Root carbohydrate content for 10 bermudagrass genotypes exposed to a 60-day drought stress by progressively lowering irrigation depth.

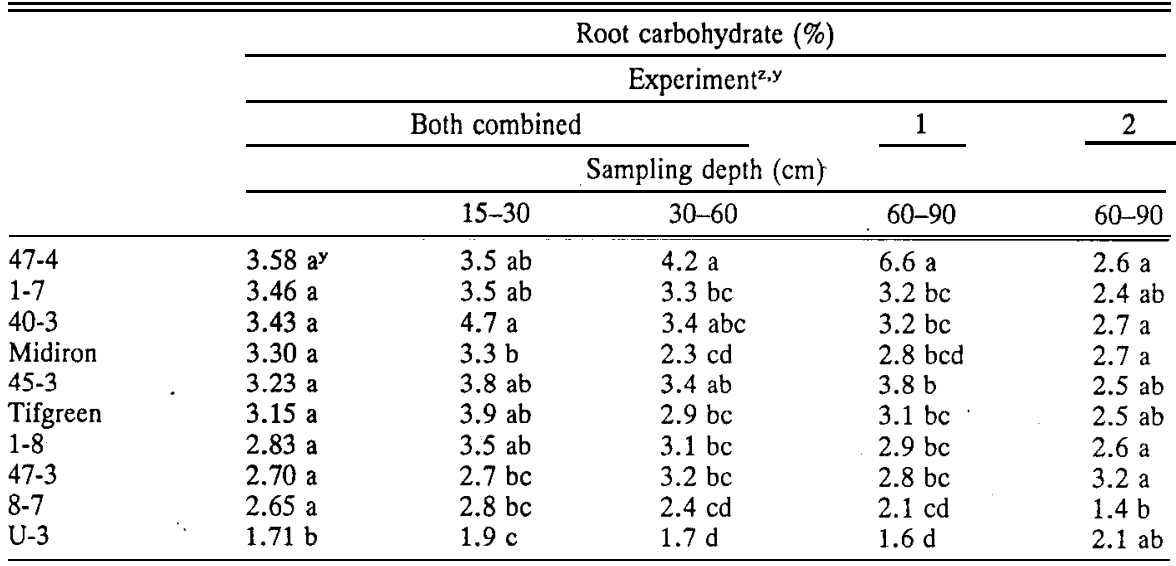

"Means for depths 0-15, 15-30, and 30-60 averaged over four replications and both experiments," and means for $60-90 \mathrm{~cm}$ averaged only over four replications, due to an experiment $\mathrm{x}$ genotype interaction at this depth.

${ }^{y}$ Means in a column followed by same letter not significantly different at $P=0.05$, using least square means procedure.

the fritted clay. Roots were dried at 49C for $48 \mathrm{hr}$ and weighed. Root weight throughout the soil profile was analyzed to determine root distribution in response to drought stress among the 10 genotypes. The dried roots were ground to pass a 40-mesh screen. A sample of the roots from each segment was used for extraction of TNC by the method of Weinmann as modified by Smith (1969). Light absorbance of the carbohydrate solution was measured on a spectrophotometer (SequoiaTurner, model 340, Mountain View, Calif.) at $490 \mathrm{~nm}$. This measurement was compared with standards of known carbohydrate concentration to determine the amount of TNC in the sample. The quantity was to estimate the percentage of TNC in the sample of roots contained in each PVC section.

Data were analyzed by the least square means procedures. Using the Pearson correlation procedure, root weight and carbohydrate content at all depths were compared with day 60 of the visual quality rankings. This procedure-was performed for both studies to observe how root weight at the various depths was related to drought avoidance as estimated by the quality ratings. To compare the root weight distribution by depth among genotypes, a natural log transformation was first performed on the root weight data. Simple linear regression was then used to fit the root weight data over varying soil depths. Finally, orthogonal contrasts were used to compare the slopes generated for the 10 genotypes.

Genotype 45-3 exhibited a high visual quality ranking at the end of both experiments (Table 1). Genotypes 47-4 and 1-7 were not consistent in visual quality between experiments; one ranked among the highest for expt. 1, but not for expt. 2.

Experimental genotype 8-7 produced significantly more top growth than any other genotype (Table 1). Also, 45-3 had significantly more top growth than 'Midiron' or 1-
8. Other genotypes that ranked high in visual quality at the end of either experiment did not necessarily have more top growth. Because top growth was not weighed after each clipping, possible periods of rapid growth were not identified. The amount of total top growth was not correlated with high visual quality.

We speculated that canopy temperature, which often corresponds directly to plant stress, might identify plants less affected by drought. However, canopy temperatures did not differ significantly among genotypes at any time in either experiment.

A significant $(P=0.05)$ experiment $\times$ genotype interaction was observed for root weight at all depths. Significant differences among genotypes were measured for root weight at depths of 15 to 30,30 to 60,60 to 90 , and 90 to $120 \mathrm{~cm}$ during expt. 1, and for all depths during expt. 2 (Table 2). No correlation between root weight by depth and visual quality was evident for expt. 1, with $r$ values ranging from 0.19 to 0.58 . However, root weights at depths of 30 to 60,60 to 90,90 to 120 , and 120 to $150 \mathrm{~cm}$ were significantly correlated with a high visual quality ranking on day 60 of expt. 2 by the Pearson correlation (Table 3). Genotypes 40$3,45-3$, and 47-4 had high root weights at these depths (Table 2) and were ranked high visually (Table 1), which may indicate a relationship to drought avoidance.

There were significant differences among the slopes representing root distribution among genotypes $(P=0.05)$. In expt. $1,1-8$ and 47-3 had the least-uniform rooting (slopes of -0.0293 and -0.0270 , respectively) among the genotypes. For expt. 2, 40-3 and 'Midiron' had the most-uniform distribution (slopes of -0.0125 and -0.0172 , respectively), while U-3 and 8-7 had the least-uniform distribution (slopes of -0.0321 and -0.0386 , respectively). No consistent trends were observed for either experiment relating mod- erate or steep slopes to high visual quality on day 60.

Differences among genotypes for percent carbohydrate occurred at depths of $\mathrm{O}$ to 15 , 15 to 30 , and 30 to $60 \mathrm{~cm}$ when data were averaged over both experiments (Table 4). However, there was a significant experiment $\mathrm{x}$ genotype interaction for percent carbohydrate in roots only at the $60-$ to $90-\mathrm{cm}$ depth $(P=0.05)$. No relationship was observed between genotype turf quality and carbohydrate content for either experiment, with $\boldsymbol{r}$ values ranging from 0.04 to 0.53 .

This study documents differences among bermudagrass genotypes regarding their ability to avoid drought stress. Results of expt. 2 suggest that the differences among the genotypes may be due to their ability to distribute roots downward in the soil profile. Plants capable of uniformly distributing their roots throughout the soil profile in response to simulated drought were superior in drought avoidance by maintaining high visual quality. We have no explanation for the lack of response in expt. 1. The ability of the various genotypes to distribute carbohydrates to the roots apparently had no relationship to their ability to avoid drought stress symptoms.

\section{Literature Cited}

Beard, J.B. 1973. Turfgrass: Science and culture. Prentice-Hall, Englewood Cliffs, N.J.

Bennett, O.L. and B.D. Doss. 1960. Effect of soil moisture level on root distribution of cool-season forage species. Agron. J. 52:204-207.

Doss, B.D., D.A. Ashley, and O.L. Bennett. 1960 Effect of soil moisture regime on root distribution of warm-season forage species. Agron J. 52:569-572.

Evans, P.S. 1978. Plant root distribution and water use patterns of some pasture and crop species. N.Z. J. Agr. Res. 21:261-265.

Hurd, E.A. 1968. Growth of roots of seven varieties of spring wheat at high and low moisture levels. Agron. J. 60:201-205.

Kemble, A.R. and H.T. McPherson. 1954. Liberation of amino acids in perennial ryegrass during wilting. Biochem. J. 58:46-49.

Reicosky, D.C., R.J. Millington, A. Klute, and D.B. Peters. 1972. Patterns of water uptake and root distribution of soybeans (Glycine max.) in the presence of a water table. Agron. J. 62:292 297.

Sheffer, K.M., J.H. Dunn, and D.D. Minner. 1987. Summer drought response and rooting depth of three cool-season turfgrasses. HortScience 22:296-297.

Smith, D. 1969. Removing and analyzing total nonstructural carbohydrates from plant tissue. Wis. Agr. Expt. Sta. Res. Rpt. 41.

Thomas, H. 1985. Water use characteristics of Dactylis glomerata L., Lolium perenne L. and L. multiflorum Lam. plants Ann. Bet. 57:211223

van Bavel, C.H.M., R. Lascano, and D.R. Wilson. 1978. Water relations of fritted clay. Soil Sci. Soc. Amer. J. 42:657-658.

Weinmann. H. 1947. Determination of total available carbohydrates in plants. Plant Physiol. 22:279-290 